\title{
A Study of the Feasibility of Using Ammonium Sulfate in Copper-Nickel Ore Processing
}

\author{
Andrey A. Goryachev ${ }^{1}$ (D), Elena V. Chernousenko ${ }^{2}$, Sergey S. Potapov ${ }^{3}$, Nikita S. Tsvetov ${ }^{4}$ \\ and Dmitriy V. Makarov ${ }^{1, *}$ \\ 1 Kola Science Centre of the Russian Academy of Sciences, Institute of North Industrial Ecology Problems, \\ Fersman St., 14a, 184209 Apatity, Russia; a.goryachev@ksc.ru \\ 2 Kola Science Centre of the Russian Academy of Sciences, Mining Institute, Fersman St., 26, \\ 184209 Apatity, Russia; chern@goi.kolasc.net.ru \\ 3 South Urals Federal Research Centre of Mineralogy and Geoecology UB RAS, 456317 Miass, Russia; \\ s_almazov@74.ru \\ 4 Kola Science Centre of the Russian Academy of Sciences, I.V. Tananaev Institute of Chemistry and Technology \\ of Rare Elements and Mineral Raw Materials, Fersman St., 26a, 184209 Apatity, Russia; n.tsvetov@ksc.ru \\ * Correspondence: mdv_2008@mail.ru; Tel.: +7-81555-79-5-94
}

Citation: Goryachev, A.A.; Chernousenko, E.V.; Potapov, S.S.; Tsvetov, N.S.; Makarov, D.V. A Study of the Feasibility of Using Ammonium Sulfate in CopperNickel Ore Processing. Metals 2021, 11, 422. https://doi.org/10.3390/ met11030422

Academic Editor: Felix A. Lopez

Received: 22 January 2021

Accepted: 28 February 2021

Published: 4 March 2021

Publisher's Note: MDPI stays neutral with regard to jurisdictional claims in published maps and institutional affiliations.

Copyright: (C) 2021 by the authors. Licensee MDPI, Basel, Switzerland. This article is an open access article distributed under the terms and conditions of the Creative Commons Attribution (CC BY) license (https:/ / creativecommons.org/licenses/by/ $4.0 /)$.

\begin{abstract}
The possibility of applying a combined concentration and metallurgical method for processing low-grade and refractory copper-nickel ores was considered. The resulting rougher and scavenger flotation concentrate contained $2.07 \%$ nickel and $0.881 \%$ copper at a recovery of $85.44 \%$ and $89.91 \%$, respectively. The concentrate was then roasted with ammonium sulfate, followed by aqueous leaching of clinker to dissolve nickel and copper. The roasting temperature, the ratio of concentrate to $\left(\mathrm{NH}_{4}\right)_{2} \mathrm{SO}_{4}$ in the mixture, and the temperature were varied. Based on the study findings, the following process conditions were found to be optimal: roasting temperature $400{ }^{\circ} \mathrm{C}$, rougher concentrate to ammonium sulfate ratio $1: 7$, and grinding size $-40 \mu \mathrm{m}$. A roasting temperature of $400{ }^{\circ} \mathrm{C}$ is significantly lower than the temperature applied in conventional pyrometallurgical processes. The possibility of collecting off-gases allows the reagent to be regenerated and makes the process even more cost-effective. End-to-end recovery into pregnant solution was $81.42 \%$ for nickel and $82.81 \%$ for copper. The resulting solutions can be processed by known hydrometallurgical methods.
\end{abstract}

Keywords: copper-nickel ore; flotation; rougher concentrate; ammonium sulfate; roasting; aqueous leaching

\section{Introduction}

To date, more than 400 copper-nickel ore deposits have been discovered worldwide, and the combined global reserves of copper and nickel are currently estimated at 1.6 billion tons and 210 million tons, respectively. Sulfide copper-nickel ore deposits account for $65 \%$ of the annual global nickel production, amounting to more than 2 million tons. In addition, about 700 thousand tons of copper and platinum group metals are produced from these ores annually [1].

Concentration feed grades are gradually deteriorating, and operators are forced to process more refractory mineral feeds $[2,3]$. Ores are characterized by a low content of valuable components, the presence of oxidized forms, and a significant share of finely disseminated sulfides. The relative simplicity and low cost of conventional concentration methods have so far allowed many major mineral processing and metal projects to operate profitably. However, the concentrates produced currently are often low-grade. Therefore, developing optimized processing flowcharts allowing for the most efficient processing of mineral feeds is a central challenge that the mining and processing industry is facing [4-7].

Long-term operation of the copper-nickel ore deposits of the Pechenga ore field (Murmansk region, Russia) has led to the need to process ores containing morphologically 
complex disseminated sulfide minerals. At the same time, conventional process flows and reagent treatments fail to achieve the desired concentration performance targets $[8,9]$. The presently prevailing ore type is disseminated serpentinite ore, making up about $80 \%$ of the ore fed to flotation. The main rock-forming minerals are serpentine, olivine, chlorite, pyroxene, and amphibole. Ore minerals are mainly represented by pyrrhotite, pentlandite, chalcopyrite, and magnetite. Sulfide grains are generally finer than $1 \mathrm{~mm}$ [10].

The concentration process flow for disseminated copper-nickel ores is composed of two-stage grinding and several flotation circuits, including inter-circuit, rougher, scavenger, cleaner flotation, and upgrading of middlings. Losses of nickel with tailings account for $25 \%-27 \%$ of the feed ore content and can increase up to $30 \%-35 \%$ when refractory finely disseminated ores are fed [8,9]. Up to $45 \%$ of the total loss is inevitable due to the fact that nickel is incorporated into the crystal lattices of various rock-forming minerals. A significant share of the loss is caused by sulfide intergrowths, which fail to be liberated at the chosen grinding size or are refractory intergrowths with silicates, where sulfide inclusions are up to $1-2 \mu \mathrm{m}$ in size $[8,10]$. In addition, some nickel is lost with the liberated pyrrhotite grains. Losses of nickel in isomorphic form with pyrrhotite average $\sim 10 \%$, but increase significantly due to inclusions of pentlandite in pyrrhotite [10].

Thus, economically and environmentally sound ways are needed to recover nonferrous metals from refractory ores.

Previously, in order to recover manganese from a low-grade carbonate manganese ore, a method of sintering the ore with ammonium sulfate followed by leaching was applied [11]. The same approach was followed in the leaching of commercial metals from the residue of spent lithium-ion batteries [12]. Ammonium sulfate was used to process converter slag with the recovery of nickel, cobalt, and copper [13].

Low-temperature roasting of a mixture of low-grade lateritic and mixed nickel ores with ammonium sulfate, followed by aqueous leaching of clinker, is considered a promising and environmentally safe process [14,15]. This process is characterized by a high degree of metal recovery, reaction selectivity, energy efficiency, and low cost.

For instance, the interactions between a mixed oxidized-sulfide nickel-containing ore concentrate with ammonium sulfate when heated up to $650{ }^{\circ} \mathrm{C}$ were studied in [15]. The concentrate contained $8.93 \%$ nickel, $0.24 \%$ cobalt, $6.51 \%$ copper, and $28.26 \%$ iron. The results showed that after roasting at $650{ }^{\circ} \mathrm{C}$ for $2 \mathrm{~h}$, the recovery of non-ferrous metals into the solution after aqueous leaching of the clinker was $70 \%$ nickel, $89 \%$ cobalt, and $90 \%$ copper, while iron almost completely passed into iron oxides-magnetite and hematite.

It was considered relevant to study the possibility of applying this method to lowgrade sulfide copper-nickel mineral feeds. Roasting followed by subsequent leaching of the concentrate produced by rougher and scavenger flotation to concentrate sulfides will make it possible to achieve a higher recovery of non-ferrous metals. This was evidenced by the concentration performance of the flotation process flow-nickel recovery into the rougher concentrate (into the rougher and scavenger flotation froth) was $\sim 10 \%$ higher than its recovery into the final concentrate (into the cleaner flotation froth).

\section{Experimental Procedure}

For the flotation tests, ore containing $0.72 \%$ nickel, $0.29 \%$ copper, $14 \%$ iron, and $2.5 \%$ sulfur was used. The ore was ground in a $7 \mathrm{~L}$ ball mill at an solid: liquid (S:L) ratio of 1:0.6 to a particle size of $80 \%$ passing $71 \mu \mathrm{m}$. The flotation tests were carried out in mechanical flotation cells with a capacity of $3 \mathrm{~L}$. Flotation was carried out in an alkaline environment at an $\mathrm{S}: \mathrm{L}$ ratio of 1:2.5. The required $\mathrm{pH}$ value was achieved by adding soda ash $\left(\mathrm{Na}_{2} \mathrm{CO}_{3}, \mathrm{SC}\right.$ «Lenreactiv», Saint Petersburg, Russia). Potassium butyl xanthate (Ltd. "AMK Khimiko Rus», Nizhny Novgorod, Russia) fed into the grinding circuit and sodium butyl aerofloat (Ltd. «MBI-Sintez», Volzhsky, Russia) were used as collectors; copper sulfate (Ltd. «Polikhim», Yekaterinburg, Russia) was used to activate sulfide minerals. The rougher flotation time was $10 \mathrm{~min}$, while the scavenger flotation time was $15 \mathrm{~min}$. 
In the roasting experiments of the rougher flotation copper-nickel concentrate, chemically pure ammonium sulfate was used. A mixture of the concentrate with ammonium sulfate was roasted in a muffle furnace (Ltd. NPF Termix, Moscow, Russia). The roasting temperature within varied from 300 to $500{ }^{\circ} \mathrm{C}$ in increments of $50{ }^{\circ} \mathrm{C}$. The roasting time was $4 \mathrm{~h}$, heating to a set temperature took $1 \mathrm{~h}$.

The mass ratio of the concentrate and ammonium sulfate was changed between 1:2 and 1:7. The roasted samples were leached with hot water at $80^{\circ} \mathrm{C}$ for $40 \mathrm{~min}$ at an S:L ratio of 1:4 and a stirring speed of $230 \mathrm{~min}^{-1}$. The resulting solution was filtered for subsequent measurement of the concentration of metals. The concentration of nickel and copper in the leach solution was measured by atomic absorption spectrometry (Shimadzu-AA7000G, Shimadzu Corp., Kioto, Japan) with electrothermal atomization (PND F 14.1:2:4.140-98).

The clinker and the leach residue were examined by powder X-ray diffraction (XRD) analysis using a DRON-2.0 instrument (JSC Burevestnik, Saint Petersburg, Russia) and copper K-alpha $(\mathrm{CuK} \alpha)$ radiation with a wavelength of $0.154184 \AA$, operated by E.D. Zenovich. X-ray diffraction patterns were interpreted by N.V. Parshina, using the XRD databases JCPDS and ASTM as references. XRD analysis makes it possible to identify phases (minerals and mineral species) in polymineral samples, provided that the sample contains at least $5 \mathrm{wt} \%$ of the mineral to be identified.

Differential scanning calorimetry (DSC) of the samples was conducted on an NETZSCH STA 409 PC/PG device (Netzsch Geraetebau GmbH, Selb, Germany), affording a synchronous recording of the DSC and thermogram (TG) curves. The recording was performed at a rate of $20^{\circ} \mathrm{C} / \mathrm{min}$, in corundum crucibles with closed lids, with a weight of $\sim 11 \mathrm{mg}$, in air.

Surface morphology analysis was performed using the scanning electron microscopy (SEM) method on an SEM LEO-420 microscope (Ltd. Carl Zeiss, Oberkochen, Germany), operated by A.T. Belyaevsky.

\section{Results and Discussion}

\subsection{Copper-Nickel Ore Flotation}

The reagent treatment and experimental results are presented in Table 1. The resulting rougher concentrate was a rougher and scavenger flotation froth containing $2.07 \%$ nickel and $0.881 \%$ copper at a recovery of $85.44 \%$ and $89.91 \%$, respectively. The losses of nickel with flotation tailings were $14.56 \%$, of copper $10.09 \%$.

Table 1. Flotation performance of the copper-nickel ore.

\begin{tabular}{|c|c|c|c|c|c|c|}
\hline \multirow{2}{*}{ Product } & \multirow{2}{*}{ Yield, \% } & \multicolumn{2}{|c|}{ Grade, \% } & \multicolumn{2}{|c|}{ Recovery, \% } & \multirow{2}{*}{ Reagent Flow Rate, g/t } \\
\hline & & $\mathrm{Ni}$ & $\mathrm{Cu}$ & $\mathrm{Ni}$ & $\mathrm{Cu}$ & \\
\hline Rougher froth & 14.03 & 3.41 & 1.61 & 66.17 & 77.28 & \multirow{5}{*}{$\begin{array}{c}\text { Rougher flotation: } \\
\mathrm{Na}_{2} \mathrm{CO}_{3}-3000, \mathrm{Kx}-100, \\
\mathrm{Af}-60, \mathrm{CuSO}-15 \\
\text { Scavenger flotation: } \\
\mathrm{Kx}-35, \mathrm{Af}-35, \mathrm{CuSO}_{4}-15\end{array}$} \\
\hline Scavenger froth & 15.77 & 0.883 & 0.234 & 19.26 & 12.63 & \\
\hline Rougher concentrate & 29.80 & 2.07 & 0.881 & 85.44 & 89.91 & \\
\hline Tailings & 70.20 & 0.150 & 0.042 & 14.56 & 10.09 & \\
\hline Feed & 100.0 & 0.723 & 0.292 & 100.0 & 100.0 & \\
\hline
\end{tabular}

$\mathrm{Na}_{2} \mathrm{CO}_{3}=$ soda ash, $\mathrm{Kx}=$ potassium butyl xanthate, $\mathrm{Af}=$ sodium butyl aerofloat, $\mathrm{CuSO}_{4}=$ copper sulfate.

\subsection{X-ray Diffraction Analysis of Clinker Samples and Leach Residue}

Three nonmetallic minerals were reliably identified in the mineral feed: talc $\mathrm{Mg}_{3} \mathrm{Si}_{4} \mathrm{O}_{10}(\mathrm{OH})_{2}$, lizardite $\mathrm{Mg}_{3} \mathrm{Si}_{2} \mathrm{O}_{5}(\mathrm{OH})_{4}$, clinochlore $(\mathrm{Mg}, \mathrm{Fe})_{5} \mathrm{Al}(\mathrm{Si}, \mathrm{Al}) \mathrm{O}_{6}(\mathrm{OH})_{8}$, and three ore minerals: chalcopyrite $\mathrm{CuFeS}_{2}$, pentlandite $(\mathrm{Fe}, \mathrm{Ni})_{9} \mathrm{~S}_{8}$, and pyrrhotite $\mathrm{Fe}_{1-x} \mathrm{~S}$. Magnetite $\mathrm{Fe}_{3} \mathrm{O}_{4}$ reflexes were also noted (Figure 1a). 


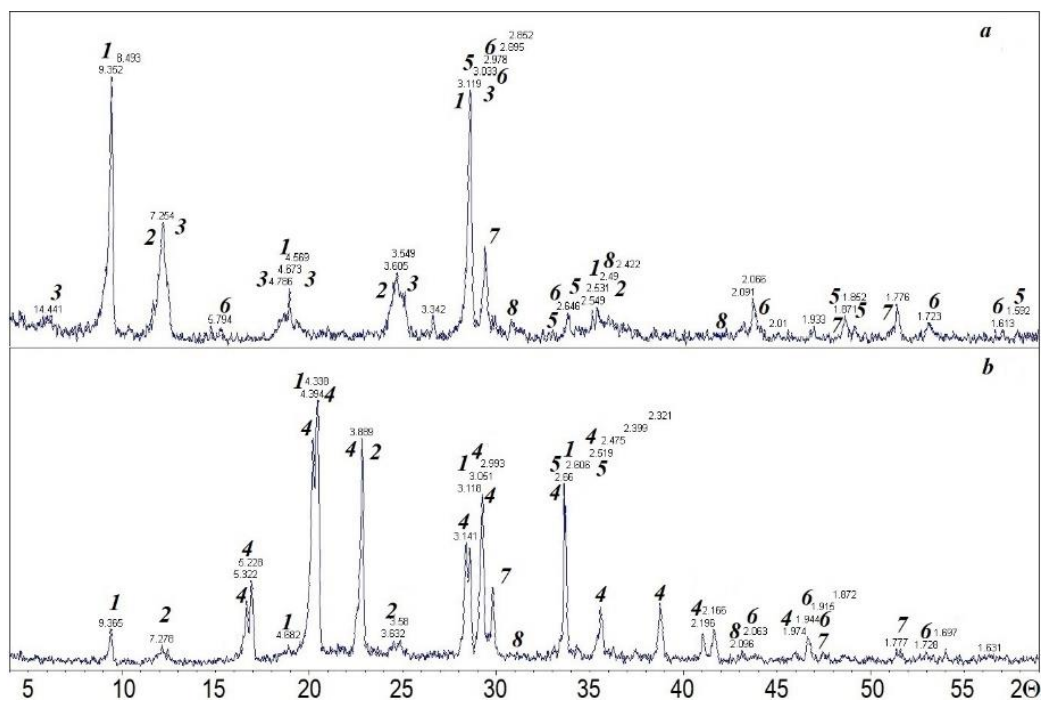

Figure 1. XRD pattern of the original concentrate (a) and of the concentrate mixture with ammonium sulfate (b). Numbers indicate reflexes: 1-talc; 2-lizardite; 3-clinochlore; 4-mascagnite; 5chalcopyrite; 6-pyrrhotite; 7-pentlandite; 8-magnetite.

When ammonium sulfate, whose natural counterpart is the mineral mascagnite $\left(\mathrm{NH}_{4}\right)_{2} \mathrm{SO}_{4}$, was added to the copper-nickel concentrate, no clinochlore was detected in the XRD pattern of the mixture. This was most likely due to a decrease in its relative content in the sample upon addition of mascagnite. The remaining minerals of the original concentrate-talc, lizardite, pyrrhotite, pentlandite, chalcopyrite and magnetite-were reliably identified (Figure $1 b$ ).

Samples of the roasted mixture of concentrate with ammonium sulfate at a ratio of $1: 2$ were used in the study. When roasting the concentrate with mascagnite at a temperature of $300{ }^{\circ} \mathrm{C}$, new minerals formed in the sample. Sulfides partially transformed into sulfate form and reflexes of nickel sulphate $\mathrm{NiSO}_{4}$ and chalcocyanite $\mathrm{CuSO}_{4} ;$ pyracmonite $\left(\mathrm{NH}_{4}\right)_{3} \mathrm{Fe}\left(\mathrm{SO}_{4}\right)_{3}$ was also noted in the sample. Mascagnite was not consumed entirely and remained in the sample. The silicate minerals were stable at high temperatures (for example, clinochlore preserves its structure until $825^{\circ} \mathrm{C}$ was reached) and remained in the sample (Figure 2a).

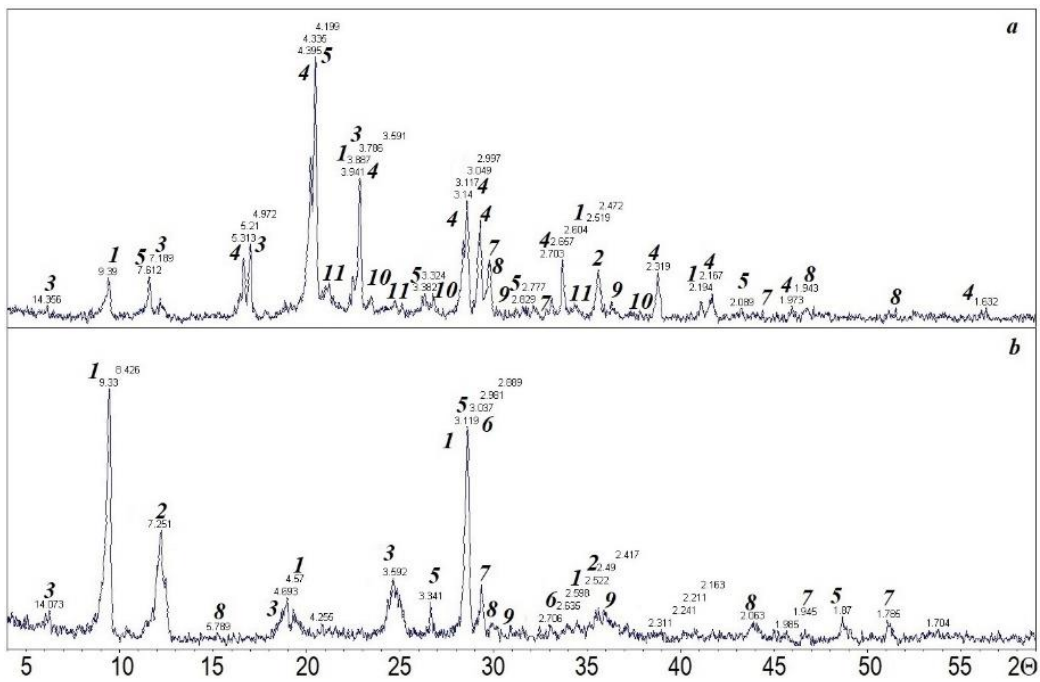

Figure 2. XRD pattern of the clinker after roasting at $300{ }^{\circ} \mathrm{C}(\mathbf{a})$ and of the leaching residue (b). Numbers indicate reflexes: 1-talc; 2-lizardite; 3-clinochlore; 4-mascagnite; 5-pyracmonite; 6-chalcopyrite; 7-pyrrhotite; 8-pentlandite; 9-magnetite; 10—nickel sulfate; 11 -chalcocyanite. 
When the sample roasted at $300{ }^{\circ} \mathrm{C}$ was leached with water, metal sulfates passed into the solution. The silicate minerals talc and lizardite remained in the sample. Sulfide minerals were also observed. This means that during roasting, the exchange reaction was incomplete and some sulfides were not converted into sulfate form (Figure $2 b$ ).

The results of roasting the concentrate with mascagnite at a temperature of $350{ }^{\circ} \mathrm{C}$ according to XRD data are shown in Figure 3a. In addition to pyracmonite $\left(\mathrm{NH}_{4}\right)_{3} \mathrm{Fe}\left(\mathrm{SO}_{4}\right)_{3}$, also formed were ammoniojarosite $\left(\mathrm{NH}_{4}\right) \mathrm{Fe}_{3}\left(\mathrm{SO}_{4}\right)_{2}(\mathrm{OH})_{6}$ and a ferruginous hydroxide phase-goethite $\alpha \mathrm{FeO}(\mathrm{OH})$. The formation of these minerals was most likely due to the iron removal from the crystal lattice of chalcopyrite, the reflexes of which were not found.

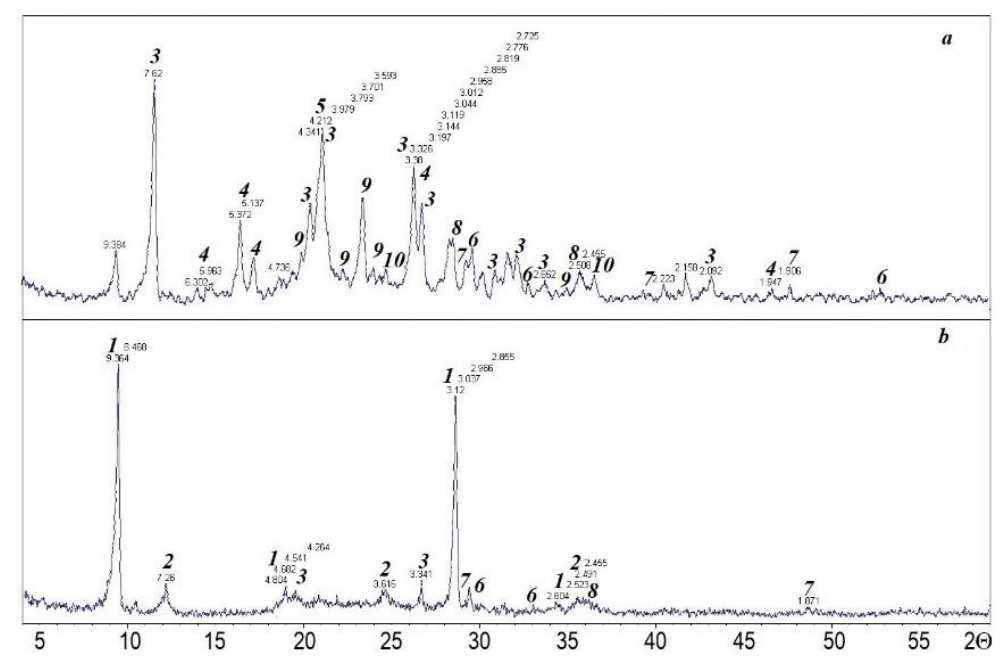

Figure 3. XRD pattern of the clinker after roasting at $350{ }^{\circ} \mathrm{C}(\mathbf{a})$ and of the leaching residue (b). Numbers indicate reflexes: 1-talc; 2-lizardite; 3-pyracmonite; 4-ammoniojarosite; 5-goethite, 6-pyrrhotite; 7-pentlandite; 8-magnetite; 9-nickel sulfate; 10—chalcocyanite.

The XRD pattern of the leach residue of the sample roasted at $350{ }^{\circ} \mathrm{C}$ is shown in Figure $3 \mathrm{~b}$. Metal sulfates passed into the solution, and as a result, the silicate minerals talc and lizardite remained in the sample. Small amounts of pyrrhotite and pentlandite reflections were observed in the sample. Almost all of the ore material likely reacted with mascagnite at a temperature of $350^{\circ} \mathrm{C}$.

After roasting the concentrate with mascagnite at a temperature of $400{ }^{\circ} \mathrm{C}$, other sulfate minerals were found in the sample: mohrite $\left(\mathrm{NH}_{4}\right)_{2} \mathrm{Fe}\left(\mathrm{SO}_{4}\right)_{2} \times 6 \mathrm{H}_{2} \mathrm{O}$ and coquimbite $(\mathrm{Fe}, \mathrm{Al})_{2}\left(\mathrm{SO}_{4}\right)_{3} \times 9 \mathrm{H}_{2} \mathrm{O}$ (Figure 4a). In addition, talc was found. It was found that with an increase in the roasting temperature to $400{ }^{\circ} \mathrm{C}$, the reflexes of nickel sulfate appeared in the sample much more intensively.

The diffraction pattern of the leach residue of the sample roasted at $400{ }^{\circ} \mathrm{C}$ is shown in Figure $4 \mathrm{~b}$. Some metals of the sulfate minerals passed into the solution (mohrite completely dissolved), but incompletely leached coquimbitite was found in the sample. The copper and nickel sulfates completely dissolve during the leaching. Nevertheless, reflexes of pyrrhotite and pentlandite were noted in the leaching residue, which indicates the need to search for ways to intensify the conversion of sulfides into sulfate form during sintering. Talc was also found.

According to XRD data of the sample roasted at $450{ }^{\circ} \mathrm{C}$, mohrite, coquimbite, and talc were found (Figure 5a). Sulfide reflexes, incompletely reacted with mascagnite, were observed. The presence of sulfides after sintering indicates the advisability of increasing the ammonium sulfate consumption. 


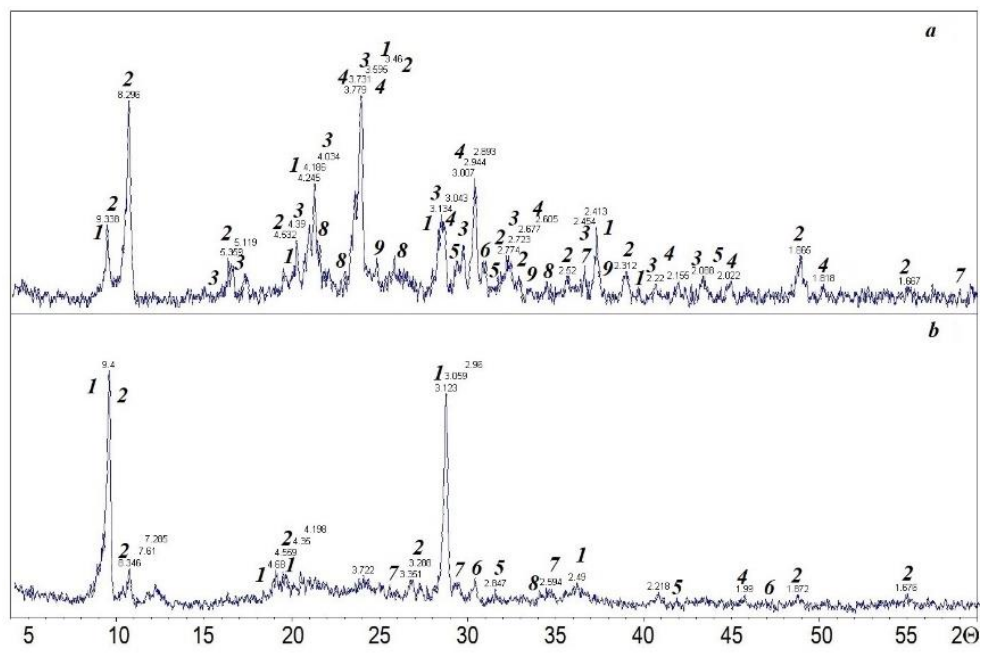

Figure 4. XRD pattern of the clinker after roasting at $400{ }^{\circ} \mathrm{C}(\mathbf{a})$ and of the leaching residue (b). Numbers indicate reflexes: 1-talc; 2-coquimbite; 3-mohrite; 4-cristobalite; 5-pyrrhotite; 6pentlandite; 7—magnetite; 8-nickel sulfate; 9-chalcocyanite.

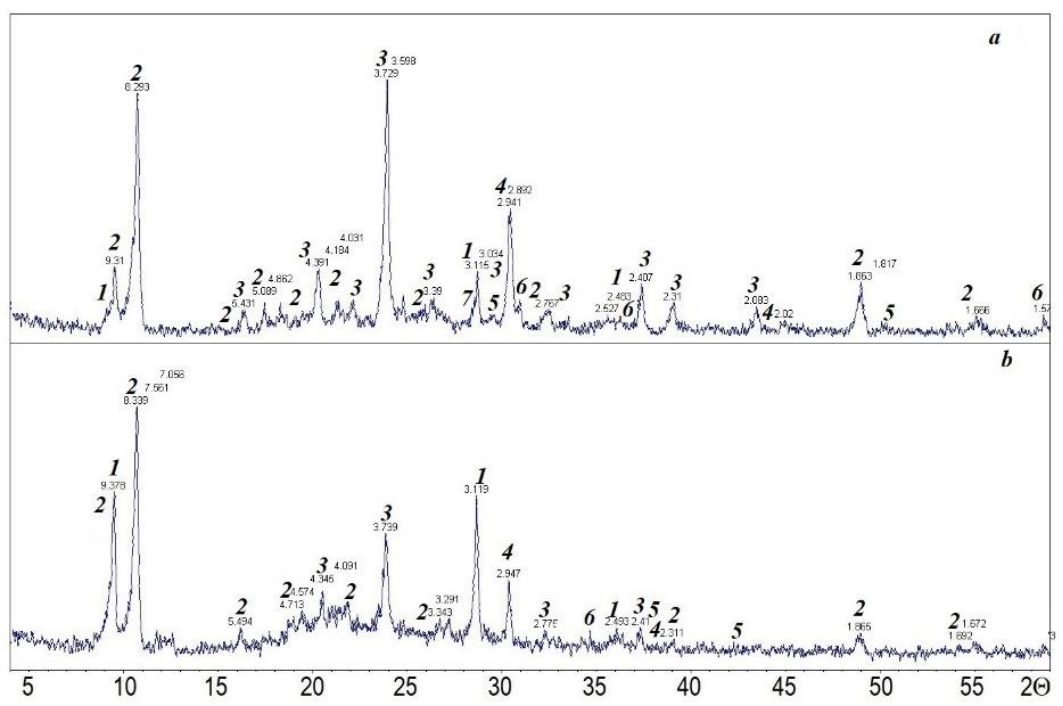

Figure 5. XRD pattern of the clinker after roasting at $450{ }^{\circ} \mathrm{C}(\mathbf{a})$ and of the leaching residue (b). Numbers indicate reflexes: 1-talc; 2-coquimbite; 3-mohrite; 4-pyrrhotite; 5-pentlandite; 6magnetite; 7-nickel sulfate.

The leached sample contained the sulfate minerals coquimbite and mohrite. Mohrite leached better than coquimbite, but also incompletely. Talc was also found (Figure 5b).

The diffraction pattern of the clinker at $500{ }^{\circ} \mathrm{C}$ is shown in Figure 6a. No sulfate minerals were detected in the sample by XRD. Primary silicate minerals of the feed concentrate were found-talc and lizardite. Reflexes of copper and nickel sulfates were also found after roasting.

Talc and lizardite were again found in the leach residue sample. The presence of quartz was somewhat likely, as its formation is possible from the initial silicate minerals (Figure 6b). 


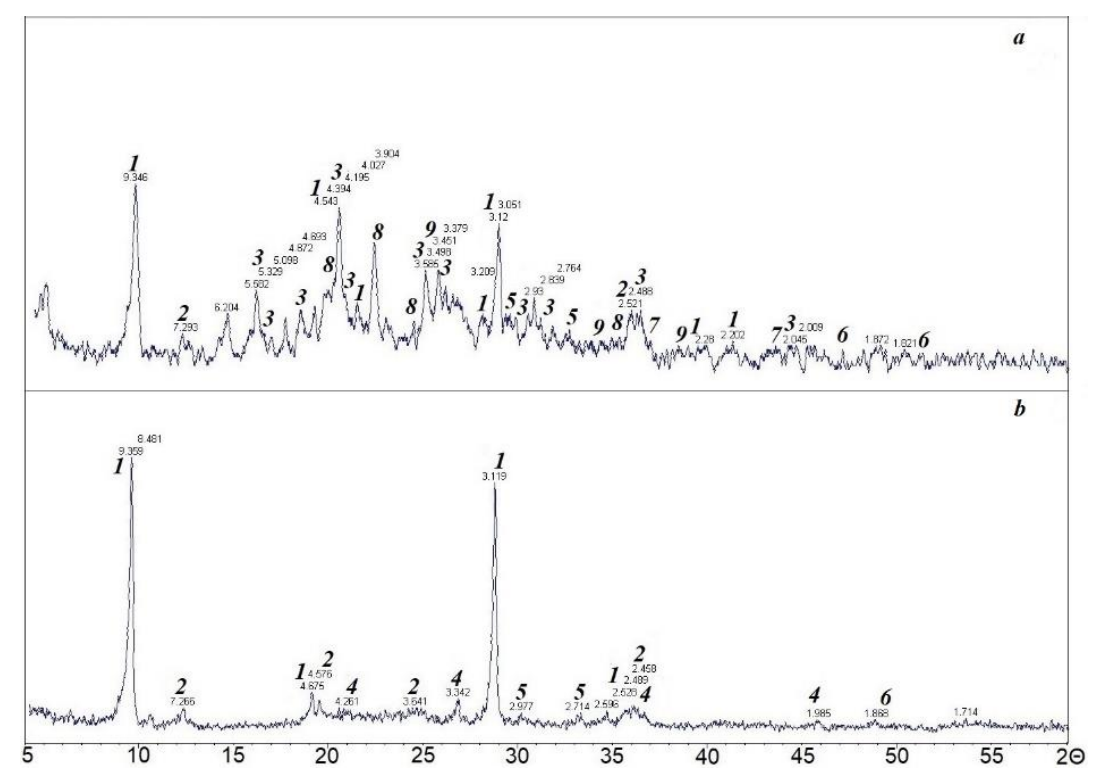

Figure 6. XRD pattern of the clinker after roasting at $500{ }^{\circ} \mathrm{C}(\mathbf{a})$ and of the leaching residue (b). Numbers indicate reflexes: 1-talc; 2-lizardite; 3-hexahydrite; 4-quartz; 5-pyrrhotite; 6-pentlandite; 7-magnetite; 8-nickel sulfate; 9-chalcocyanite.

\subsection{TG-DSC Study of a Concentrate Mixture with Ammonium Sulfate}

There exists a considerable body of research on the behavior of sulfides, silicates, and concentrates when heated both in air and in other environments [16-23]. In this case, the process is accompanied by the interaction of minerals with ammonium sulfate. Typical thermogram-differential scanning calorimetry (TG-DSC) curves of a concentrate mixture with ammonium sulfate at a ratio of 1:2 are shown in Figure 7 . In the low-temperature region below $300{ }^{\circ} \mathrm{C}$, almost no weight loss of the mixture was observed. However, when the talc in the mixture was heated, the removal of sorption water at $200{ }^{\circ} \mathrm{C}$ could be observed. The pronounced endothermic effects with minima at 332 and $436.3{ }^{\circ} \mathrm{C}$ were due to thermal decomposition of molten ammonium sulfate, which has not completely interacted with concentrate minerals. Upon further heating, a series of endothermic effects were observed with minima at $439,469.4,495.8$, and $549.1^{\circ} \mathrm{C}$, accompanied by loss of sample mass. These are difficult to interpret unambiguously. These effects are most likely associated with the decomposition of complex ammonium-containing iron sulfates. Note also that in this temperature range, exothermic oxidation processes of the sulfide minerals in the concentrate occurred with increasing weight. The subsequent endothermic effects at 694.7 and $886.6{ }^{\circ} \mathrm{C}$, accompanied by a decrease in the sample weight, were due to the dehydration of lizardite and talc.

\subsection{The Effect of the Roasting Temperature on the Recovery of Metals into Solution}

According to the experimental data collected at various roasting temperatures, it was found that at $300{ }^{\circ} \mathrm{C}$, the recovery of the metals was the lowest in the entire roasting temperature range- $2.0 \%$ for nickel and $4.9 \%$ for copper (Figure 8). An increase in the roasting temperature to 350 and $400{ }^{\circ} \mathrm{C}$ led to an increase in the recovery of metals. 


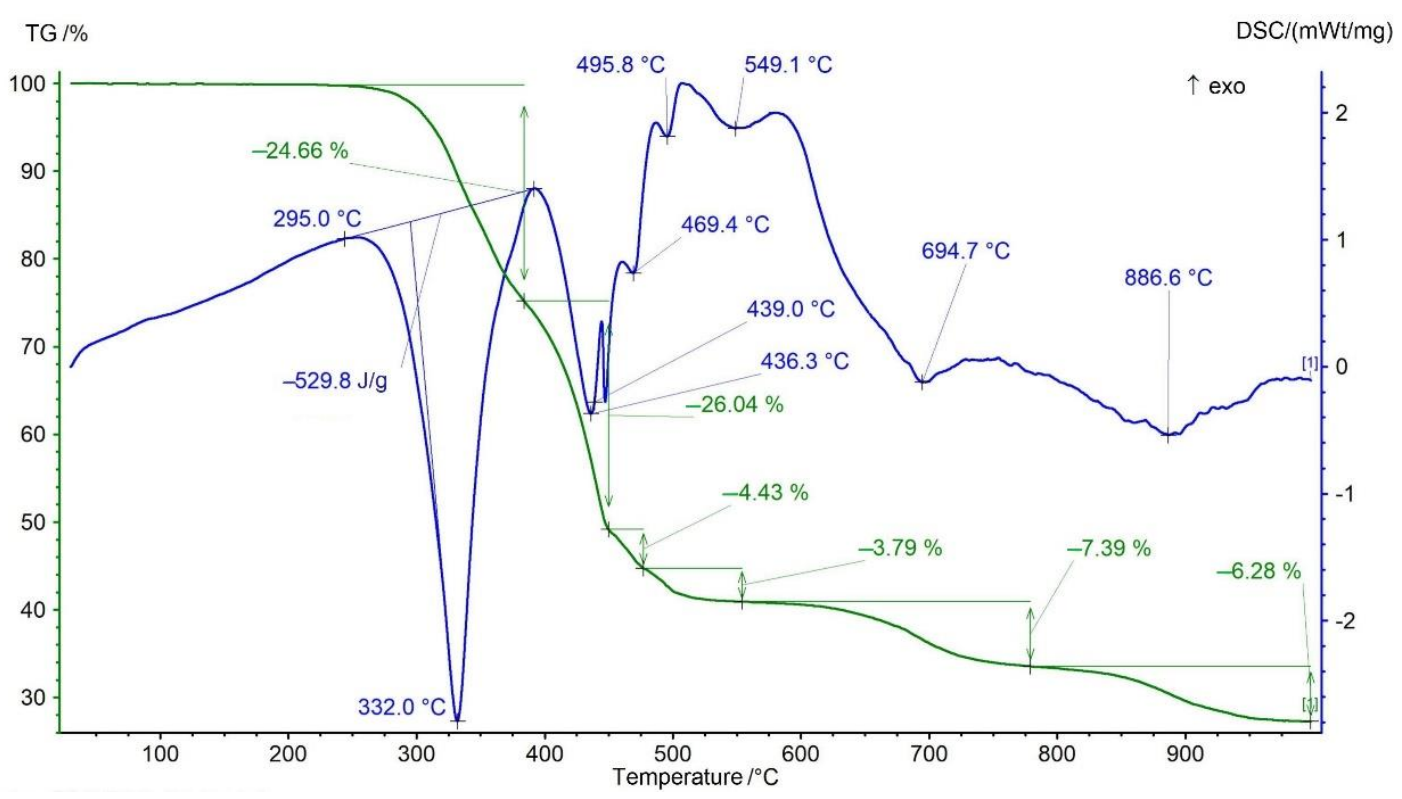

Figure 7. TG-DSC curves of a concentrate mixture with ammonium sulfate at a ratio of 1:2.

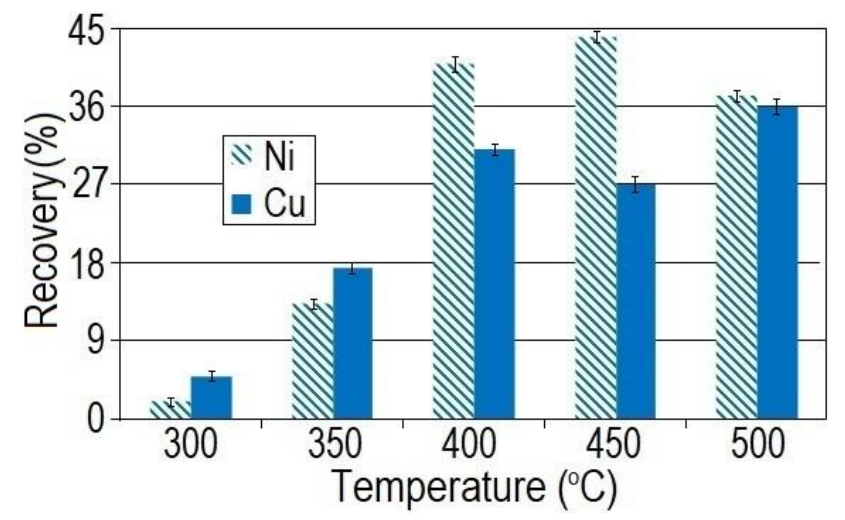

Figure 8. Recovery of metals into solution depending on the roasting temperature of a 1:2 mixture of concentrate and ammonium sulfate.

Figure 7 shows that the highest nickel recovery was achieved at a roasting temperature of $450{ }^{\circ} \mathrm{C}$, while almost $44 \%$ passed into the solution. The subsequent decrease in the recovery can be explained by a decrease in the amount of the reagent involved in the reaction due to the decomposition of ammonium sulfate and ammonium hydrosulfate into $\mathrm{SO}_{3}$ and $\mathrm{NH}_{3}$ forms.

The highest copper recovery was achieved at a roasting temperature of $500{ }^{\circ} \mathrm{C}$; at this temperature, $36 \%$ of the metal was recovered into the solution (Figure 8 ).

\subsection{The Effect of the Concentrate to Ammonium Sulfate Ratio on the Recovery of Metals into Solution}

The results of experiments with varying roasting temperatures showed that it is possible to achieve an acceptable level of recovery even at a temperature of $400{ }^{\circ} \mathrm{C}$. The effect of the concentrate to ammonium sulfate ratio on the recovery of metals into solution was studied at this temperature.

An analysis of the recovery performance at different ratios of concentrate to ammonium sulfate showed that the recovery of nickel into the solution was the highest at a ratio of $1: 7-77 \%$ (Figure 9). The recovery of copper tended to increase as the share of ammonium sulfate in the sintered mixture increased. At a ratio of 1:7, 79\% of the copper was recovered, while at 1:3 the recovery was as low as $55 \%$. 


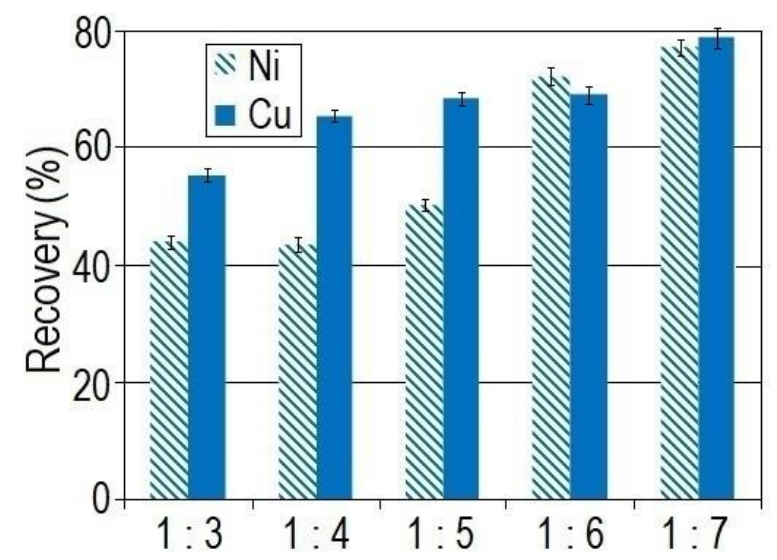

Figure 9. Recovery of metals into solution depending on the concentrate to ammonium sulfate mass ratio at a roasting temperature of $400{ }^{\circ} \mathrm{C}$.

\subsection{The Effect of Grinding on the Recovery of Metals into Solution}

In order to increase the recovery of non-ferrous metals into the solution, the effect of concentrate grinding was studied. Grinding was together with ammonium sulfate. The experiments were carried out for size classes of $-64,-50$, and $-40 \mu \mathrm{m}$ (Figure 10).

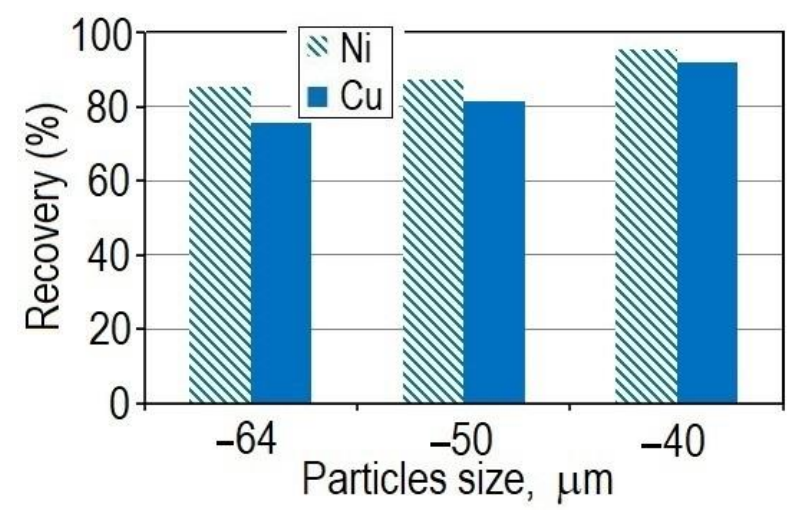

Figure 10. Recovery of metals into solution depending on the grinding.

The experiments were carried out at an optimum temperature of $400{ }^{\circ} \mathrm{C}$ and a concentrate to ammonium sulfate ratio of 1:7. Grinding the mixture to $-50 \mu \mathrm{m}$ recovered $87.1 \%$ nickel and $81.4 \%$ copper. Finer grinding made it possible to increase the recovery of non-ferrous metals. $95.3 \%$ of nickel and $92.1 \%$ of copper was recovered into the solution.

Figure 11a shows the typical surface of the concentrate particles, characterized by an angular particle shape with curved surfaces. Figure $11 \mathrm{~b}$ shows the morphology of the concentrate mixture with ammonium sulfate. The mixture is in the form of agglomerates with ammonium sulfate particles enveloping the particles of the concentrate. The clinker particle morphology after roasting at $400^{\circ} \mathrm{C}$ is given in Figure 11c. One can see the interaction products of sulfide minerals and ammonium sulfate, predominantly lamellar and, to a lesser extent, rod-shaped. Porosity is noted, likely associated with the decomposition of ammonium sulfate. Finally, Figure 11d shows the surface of the leach residue. The appearance of the particles is close to the initial concentrate. 


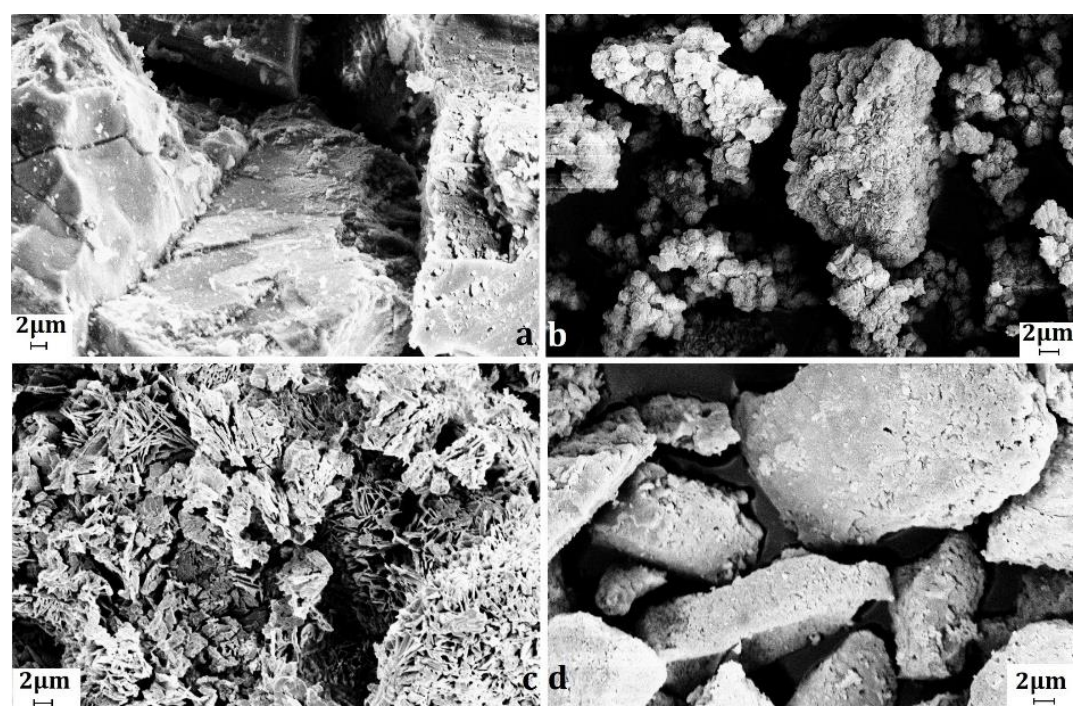

Figure 11. Particle morphology of the concentrate (a), concentrate mixture with ammonium sulfate at a ratio 1:7 (b), clinker after roasting at $400{ }^{\circ} \mathrm{C}(\mathbf{c})$, and leach residue (d).

\section{Conclusions}

The feasibility of using ammonium sulfate in combined copper-nickel ore processing flowcharts was investigated. Low-temperature roasting of the rougher concentrate, followed by water leaching of clinker, is a promising and environmentally safe process, which significantly reduces atmosphere pollution, while ammonium sulfate can be recycled.

In addition, this method makes possible cost-effective processing of low-grade concentrates of non-ferrous metals.

Laboratory experiments were carried out involving sintering of the rougher coppernickel concentrate (nickel $2.07 \%$ and copper $0.881 \%$ ) with ammonium sulfate. Sintering at $400{ }^{\circ} \mathrm{C}$, a mixture with a concentrate to ammonium sulfate ratio of $1: 7$ preliminarily ground to $-40 \mu \mathrm{m}$ resulted in the following recoveries in the subsequent aqueous leaching stage: nickel $95.3 \%$ and copper $92.1 \%$. The resulting solutions can be processed by known hydrometallurgical methods.

End-to-end recovery into the pregnant solution in the combined flotation and metallurgical process flow amounted to $81.42 \%$ for nickel and $82.81 \%$ for copper. Experimental work to optimize the process parameters will continue.

Author Contributions: Conceptualization, A.A.G., E.V.C., S.S.P., N.S.T., and D.V.M.; methodology, A.A.G., E.V.C., S.S.P., N.S.T., and D.V.M.; investigation, A.A.G., E.V.C., S.S.P., N.S.T., and D.V.M.; writing—original draft preparation, A.A.G., E.V.C., S.S.P., N.S.T., and D.V.M.; writing—review and editing, A.A.G., E.V.C., S.S.P., N.S.T., and D.V.M.; visualization, A.A.G., E.V.C., S.S.P., N.S.T., and D.V.M. All authors have read and agreed to the published version of the manuscript.

Funding: This research was funded by Russian government grant nos. 0226-2019-0047 and 0226-20190011. The research was financially supported by the Kolarctic CBC 2014-2020 programme, project no. KO1030 "Supporting Environmental Economic and Social Impacts of Mining Activity."

Institutional Review Board Statement: Not applicable.

Informed Consent Statement: Not applicable.

Data Availability Statement: Data available in a publicly accessible repository.

Conflicts of Interest: The authors declare no conflict of interest. 


\section{References}

1. Mantsevich, M.I.; Malinsky, R.A.; Khersonsky, M.I.; Lapshina, G.A. Search for methods to improve the grade of copper-nickel concentrates. Min. Inf. Anal. Bull. 2008, 7, 359-363. (In Russian)

2. Batterham, R.J.; Robinson, D.J. The future of mining: Will in place recovery ever come of age? In Proceedings of the XXIX International Mineral Processing Congress 2018, Moscow, Russia, 17-21 September 2018; Ore and Metals: Moscow, Russia, 2018; pp. 13-22.

3. CSIRO. Producing More from Less. 2015. Available online: https://www.csiro.au/en/Research/MRF/Areas/Resourcefulmagazine/ Issue-07/Producing-more-from-less (accessed on 14 December 2020).

4. Algebraistova, N.K.; Mikheev, V.G.; Markova, S.A.; Gaivoronskaya, M.V.; Kondratieva, A.A.; Groo, E.A.; Razvyaznaya, A.V. Technological assessment of impregnated copper-nickel ore processing. Min. Inf. Anal. Bull. 2013, 2, 56-67. (In Russian)

5. Kirjavainen, V.; Heiskanen, K. Some factors that affect beneficiation of sulphide nickel-copper ores. Min. Eng. 2007, 20, 629-633. [CrossRef]

6. Zhao, K.L.; Gu, G.H.; Wang, H.; Wang, C.L.; Wang, X.H.; Luo, C. Influence of depressant foenum-graecum on the flotation of a sulfide ore which contains hydrophobic gangue. Int. J. Miner. Proc. 2014, 141, 68-76. [CrossRef]

7. Bao, Y.; Xu, G.; Tian, X.; Xu, P.; Ma, J. Effect of ammonia molecules on the separation of pentlandite from serpentine using copper (II) as activator. Sep. Purif. Technol. 2018, 200, 242-254. [CrossRef]

8. Chernousenko, E.V.; Neradovsky, Y.N.; Kameneva, Y.S.; Vishnyakova, I.N.; Mitrofanova, G.V. Increasing efficiency of Pechenga rebellious copper-nickel sulphide ore flotation. J. Min. Sci. 2018, 54, 1035-1040. [CrossRef]

9. Kopylov, V.V.; Nesterov, K.V.; Kurbatov, E.A.; Molodtsev, M.S. The efficient practice of processing refractory ores at Kola MMC's concentrator plant. Tsvetnye Met. 2020, 3. (In Russian) [CrossRef]

10. Likhacheva, S.V.; Neradovskiy, Y.N. Decreasing of losses of nickel with flotation tailings of Pechenga copper-nickel ores. Tsvetnye Met. 2013, 10, 37-40. (In Russian)

11. Zhu, G.C.; Li, F.P.; Xiao, M.G. Process of enriching and recovering Mn by roasting the low-grade manganese carbonate ore with ammonium sulfate. J. Guilin Univ. Technol. 2005, 25, 534-540.

12. Li, D.F.; Wang, C.Y.; Yin, F.; Chen, Y.Q.; Jie, X.W.; Yang, Y.Q.; Wang, J. Leaching of valuable metals from roasted residue of spent lithium-ion batteries with ammonium sulfate. Chin. J. Proc. Eng. 2009, 2, 264-268.

13. Sukla, L.B.; Panda, S.C.; Jena, P.K. Recovery of cobalt, nickel and copper from converter slag through roasting with ammonium sulphate and sulphuric acid. Hydrometallurgy 1986, 16, 153-165. [CrossRef]

14. Mu, W.; Cui, F.; Huang, Z.; Zhai, Y.; Xu, Q.; Luo, S. Synchronous extraction of nickel and copper from a mixed oxidesulfide nickel ore in a low-temperature roasting system. J. Clean. Prod. 2018, 177, 371-377. [CrossRef]

15. Li, G.; Xiong, X.; Wang, L.; Che, L.; Wei, L.; Cheng, H.; Zou, X.; Xu, Q.; Zhou, Z.; Li, S.; et al. Sulfation roasting of nickel oxide-sulfide mixed ore concentrate in the presence of ammonium sulfate: Experimental and DFT studies. Metals 2019, 9, 1256. [CrossRef]

16. Dunn, J.G. The oxidation of sulphide minerals. Therm. Acta 1997, 300, 127-139. [CrossRef]

17. Dorogina, G.A.; Gulyaeva, R.I.; Selivanov, E.N.; Balakirev, V.F. Thermal and thermomagnetic properties of pyrrhotites. Rus. J. Inorg. Chem. 2015, 60, 301-306. [CrossRef]

18. Xia, F.; Pring, A.; Brugger, J. Understanding the mechanism and kinetics of pentlandite oxidation in extractive pyrometallurgy of nickel. Min. Eng. 2012, 27-28, 11-19. [CrossRef]

19. Sahyoun, C.; Kingman, S.W.; Rowson, N.A. The effect of heat treatment on chalcopyrite. Phys. Sep. Sci. Eng. 2003, 12, 23-30. [CrossRef]

20. Yu, D.; Utigard, T.A. TG/DTA study on the oxidation of nickel concentrate. Therm. Acta 2012, 533, 56-65. [CrossRef]

21. Ivanova, V.P.; Kasatov, B.K.; Krasavina, T.N.; Rozinova, E.L. Thermal Analysis of Minerals and Rocks; Nedra: Leningrad, Russia, 1974; p. 399. (In Russian)

22. Popov, Y.V.; Zhabin, A.V.; Pustovit, O.E. Mineral composition of serpentinites of the tectonic melange of the Dakhovsky crystalline protrusion (Greater Caucasus). Geol. South Russ. 2019, 9, 38-48. (In Russian)

23. Zulumyan, N.; Isahakyan, A.; Beglaryan, H.; Melikyan, S. A study of thermal decomposition of antigorite from duniteand lizardite from peridotite. J. Therm. Anal. Calorim. 2018, 131, 1201-1211. [CrossRef] 